\title{
Association of the SLC6A4, SLC6A3, COMT and $B D N F$ Gene Polymorphisms with Suicidal Behavior: A Case Control Study
}

Ekaterina Rafikova ( $\sim$ kat.rafikov@gmail.com )

Institut biologii gena Rossijskoj akademii nauk https://orcid.org/0000-0003-2905-4021

Maria I. Shadrina

Institute of Molecular Genetics RAS

Peter A. Slominsky

Institute of Molecular Genetics RAS

Alla B. Guekht

Moscow research and Clinical Center of Neuropsychiatry of Healthcare Department

Aleksei P. Ryskov

Institute of Gene Biology RAS

Dmitry V. Shibalev

Institute of Gene Biology RAS

Vasiliy A. Vasilyev

Institute of Gene Biology RAS

Research article

Keywords: Gene polymorphism, suicidal behavior, depressive symptoms, anxiety

Posted Date: August 21st, 2020

DOI: https://doi.org/10.21203/rs.3.rs-56679/v1

License: (9) This work is licensed under a Creative Commons Attribution 4.0 International License.

Read Full License 


\section{Abstract}

\section{Background}

Suicide causes about 1 million deaths per year. Familial transmission of suicide, as well as the involvement of serotonin and dopamine systems in suicidal behavior, was confirmed by previous studies. We investigated an effect of 11 polymorphisms of 9 genes related to dopamine and serotonin transmission (SLC6A4, HTR1A, HTR2A, HTR1B, SLC6A3, DRD4, DRD2, COMT, and BDNF) on the risk of suicide.

Methods

The study was performed on 100 psychiatric clinic patients with repeated suicide attempts. Genomic DNA was obtained from venous blood. Genotyping was performed using locus-specific PCR. Statistical analysis was carried out using a Pearson Chi-squared test, ORs, with the corresponding $95 \% \mathrm{Cls}$ and oneway ANOVA.

Results

Association of the SLC6A3 40-45 bp VNTR and SLC6A4 rs25531 loci with suicidal behavior was tested for the first time. We have shown that a short allele of SLC6A3 40-45 bp VNTR locus might increase the risk of suicidal attempts $(p=0.009)$. Contrary to previous research, we have found that the Val-allele of COMT rs4680 is associated with suicide $(\mathrm{p}=0.028)$. T-allele of BDNF rs6264 and A-allele of SLC6A4 rs25531 were associated with suicidal behavior with $p=0.029$ and $p=0.047$, respectively. ANOVA showed the lack of association between these loci and severity of depressive symptoms, but revealed a possible effect of SLC6A4 40 bp VNTR and HTR1B loci on anxiety symptoms.

Conclusions

Our results suggest that allelic variants of $S L C 6 A 3, S L C 6 A 4, C O M T$ and BDNF genes might be considered as risk factors for repeated suicide attempts in patients with different mental disorders. Loci SLC6A4 40 bp VNTR and HTR1B rs6296 may affect anxiety symptoms.

\section{Background}

According to the World Health Organization, more than 800000 people die from suicide each year [1]. Many family, twin, and adoption studies provide evidence for familial transmission of suicide and suicidal behavior [2-6]. The contribution of genetic risk factors was confirmed even after controlling for hereditary mental disorders [7]. The aggregation of suicide in families also cannot be fully explained by a similar environment [8]. Molecular studies have shown that suicide attempts could be associated with altered serotonin (HT) and dopamine (DA) transmission [9-12]. Given the above data, the search for an association between suicidal behavior and genes encoding important pathways of serotoninergic and 
dopaminergic transmission (HT and DA transporters, receptors, ferments for HT and DA biosynthesis) is relevant.

The promoter region of the serotonin transporter gene (SLC6A4/5HTT) contains the variable number of tandem repeats (VNTR-polymorphism). The short (S) allele with 14 repeats is associated with lower expression activity than the long $(L)$ allele with 16 repeats $[13,14]$. Later, a single nucleotide polymorphism (SNP) $A \rightarrow G$ (rs25531) was detected within the sixth repeat of the S-and L-alleles. It was shown that the expression level of the $L_{G}$ allele is lower than of the $L_{A}$ allele. A meta-analysis of 39 studies of the SLC6A4 VNTR-polymorphism demonstrated a significant association between suicidal behavior and the S-allele. The influence of the rs 25531 polymorphism was not considered in this study [15].

Polymorphism C1019G (rs6295) exists in the promoter region of the HTR1A gene. It might enhance or decrease gene expression depending on the location on the presynaptic or postsynaptic membrane [16, 17]. Post-mortem study has discovered that the HTR1B gene polymorphism G861C (rs6296) affects gene expression activity and as a result changes the density of the receptors [18]. In the case of HTR1A gene polymorphism A1438G (rs6311), it was shown that the A-allele increases the promoter activity [19]. Association studies for these genes were also performed. Meta-analyses of these investigations detected a significant association between HTR2A (rs6311) and suicidal behavior [20] but failed to find any associations for HTR1A (rs6295) and HTR1B (rs6296) polymorphisms [21, 22].

A 40-45 bp VNTR-polymorphism exists in the 3'-UTR region of the transporter gene (SLC6A3/DAT1). Several studies have confirmed the effect of the length of this locus on gene expression, although contradictory results have been obtained [23-26]. It was shown that the 9R-allele may result in a high risk of depression and angry-impulsive personality traits $[27,28]$. The dopamine receptor gene (DRD4) contains a $48 \mathrm{bp}$ VNTR-polymorphism in exon 3 and $120 \mathrm{bp} \mathrm{In} /$ Del polymorphism in the promoter region. The 7-repeat variant of the DRD4 VNTR-polymorphism was found to be associated with such personal traits as impulsivity, aggression, depression and novelty-seeking behavior [29, 30]. DRD4 In/Del polymorphism might affect gene expression activity-the long allele is associated with lower expression level than the short allele [31]. The density of the DRD2 receptors in the striatum depends on the allelic variant of the rs1800497 (C/T) polymorphism. It was shown that T-allele carriers have a lower density of DRD2 receptors [32]. The DRD2 rs 1800497 polymorphism is associated with impulsivity and suggested to be related to suicidal attempts $[33,34]$. The enzyme catechol-0-methyltransferase (COMT) plays an important role in dopamine metabolism. SNP rs4680 (G/A or Val/Met) in the COMT gene leads to reduced enzyme activity [35]. A meta-analysis of six studies has demonstrated that the COMT rs 4680 polymorphism has a modestly significant association with suicidal behavior [22].

Another gene associated with mental disorders is the brain-derived neurotrophic factor (BDNF) gene [36]. BDNF and serotonin are shown to regulate each other positively: $\mathrm{HT}$ increases the BDNF expression and BDNF stimulates HT neurons' growth and survival [37]. The BDNF gene contains a common 
polymorphism rs6264 which leads to the replacement of methionine with valine (Val66Met). Met-allele is associated with decreased protein activity [38] and possibly with suicide attempts [39].

This study aims to estimate the contribution of 11 polymorphisms in the genes SLC6A4 (5HTT), HTR1A, HTR2A, HTR1B, SLC6A3 (DAT1), DRD4, DRD2, COMT and BDNF to suicidal behavior and severity of symptoms of depression and anxiety in patients. As described above, all polymorphisms under study affect gene expression, protein product activity or were shown to be associated with personality traits.

\section{Methods}

\subsection{Subjects}

A sample of patients $(N=100)$ who had attempted suicide at least two times and were monitored by a psychotherapist was used for this study. A survey of patients and blood samples was carried out at the Moscow Research and Clinical Center for Neuropsychiatry of the Healthcare Department of Moscow. Depressive symptoms were evaluated with help of Hamilton's Depression Rating Scale (HAMD) and Beck's Depression Inventory (BDI). Spielberger's test was used for evaluation of the degree of situational and personal anxiety. Demographic and clinical characteristics of samples and results of medical examinations of patients are shown in Table 1. Detailed data of the patient's characteristics are shown in Additional file 1. The control group $(\mathrm{N}=200)$ was a sample of the East Slavic population of the city of Moscow and the regions of Central Russia (99 men (49.5\%) and 101 women (50.5\%); mean age: $36 \pm 8.2$ years).

\subsection{DNA isolation and genotyping}

Genomic DNA was obtained from $250 \mu \mathrm{L}$ of EDTA-anticoagulated venous blood using innuPREP Blood DNA Mini Kit (Analytik Jena AG, Germany), according to the manufacturer's recommendations.

The SNP and VNTR genotyping was carried out using locus-specific PCR as described previously [40-45].

\subsection{Statistical analysis}

Hardy-Weinberg equilibrium calculator software (https://wpcalc.com/en/equilibrium-hardy-weinberg/) was used to calculate the correspondence of the genotype distribution in the population sample to the Hardy-Weinberg equilibrium. Allele and genotype frequencies between cases and control groups were compared using a Pearson Chi-squared test. The strength of associations between allelic variants of studied polymorphic loci and suicidal behavior was estimated using odds ratios (ORs), with the corresponding $95 \%$ confidence intervals ( $95 \% \mathrm{Cls}$ ). One-way ANOVA was performed to determine the effect of studied polymorphisms on symptoms of depression, situational anxiety, and personal anxiety. The normal quantile-quantile (QQ) plot and Shapiro-Wilk test were used to test whether our data were 
normally distributed. The analysis of frequencies of genotypes and alleles, Chi-squared test and ANOVA were conducted using Statistica (data analysis software system, version 7, http://www.statsoft.com). All tests were conducted at a level of significance $p<0.05$.

\section{Results}

In the control samples, all polymorphisms were in the Hardy-Weinberg equilibrium. The results of the polymorphic loci genotyping in cases and control samples are shown in Table 2.

The strongest association was found for VNTR-polymorphism of the SLC6A3 gene. Given the data suggesting the effect of length of this locus on gene expression and high activity of the 10R allele compared with the $9 \mathrm{R}$ allele [23-26], we classified cases and controls as carriers of the long $(\geq 10)$ and short $(<10)$ alleles. The short allele $(S)$ was more common in cases than it was in the control group $(p=0.009)$. SS and LS genotype frequencies were higher and LL genotype frequency was lower in cases than in controls $(p=0.019)$.

Another gene of the dopaminergic system associated with suicide attempts was the COMT gene. In the group of cases, the G-allele (Val) frequency of COMT rs4680 was significantly higher than with the control group ( $p=0.028$ ). However, the genotype distributions of COMT rs4680 were not found to be significantly different between cases and controls, AA genotype frequency was decreased and GA and GG frequencies were increased in the group of cases compared with the control group $(17 \%, 53 \%, 30 \%$, respectively, in cases and $29.4 \%, 47.9 \%, 22.7 \%$, respectively, in controls; $p=0.064$ ).

We also found a statistically significant association between the T-allele of $B D N F$ rs6264 and suicidal behavior. In the group of patients, the T-allele was more common than with controls $(p=0.029)$. The difference in genotype distribution was not statistically significant. However, CC genotype tends to be less common in the group of cases, while frequencies of CT and TT genotypes are higher in cases than with the control group $(61 \%, 32 \%, 7 \%$, respectively, in cases and $70.7 \%, 26.6 \%, 2.7 \%$, respectively, in controls; $p$ $=0.076)$.

We analysed two loci of the SLC6A4 gene: rs25531 and VNTR 44 bp polymorphism. We found that the rs25531 polymorphism of SLC6A4 showed some statistically significant associations. The A-allele frequency of rs 25531 was higher in cases than it was in controls $(p=0.047)$. VNTR-polymorphism of SLC6A4 was not found to be associated with suicidal behavior.

Because of the complexity of SLC6A4 organization, we additionally analysed the distribution frequencies of its allelic variants according to their functional characteristics. To verify whether alleles with low or high expression activity are associated with suicidal behavior, we grouped alleles and genotypes according to their expression levels: high $\left(\mathrm{L}_{\mathrm{A}}\right)$ and low $\left(S\right.$ and $\left.\mathrm{L}_{\mathrm{G}}\right)$ alleles with high and low expression activity, respectively, and high/high $\left(\mathrm{L}_{A} / \mathrm{L}_{A}\right)$, high/low $\left(\mathrm{L}_{A} / \mathrm{S}_{A}, \mathrm{~L}_{A} / \mathrm{L}_{G}\right)$ and low/low $\left(\mathrm{S}_{A} / \mathrm{S}_{A}, \mathrm{~S}_{A} / \mathrm{L}_{G}, \mathrm{~L}_{G} / \mathrm{L}_{G}\right)$ genotypes. 
We found that the distribution of SLC6A4 gene genotypes and alleles showed that alleles with high expression tend to be increased in patients with suicidal behavior compared with the control group, but this association was not statistically significant $(p=0.098)$.

The alleles of the dopamine receptor DRD4 exon 3 were grouped into long $(\geq 7)$ and short $(<7)$ allelic variants, associations between this locus and suicide were not found. No significant associations between suicidal behavior and DRD2 rs1800497, DRD4 In/Del, 5HTR1A rs6295, 5HTR2A rs6311 and $5 H T R 1 B$ rs6296 alleles and genotypes were discovered. All results of genotyping of cases and controls are shown in Additional files 1 and 2, respectively.

To determine the effect of studied polymorphisms on the patient's clinical characteristics we conducted the one-way ANOVA. This analysis showed the lack of association between loci which were significant in the Chi-squared test and severity of the symptoms of depression, situational anxiety, and personal anxiety in patients with suicidal behavior. However, we observed a significant effect of SLC6A4 VNTR 44 bp on the situational anxiety and HTR1B loci on the personal anxiety $(p=0,0358$ and $p=0,0132$, respectively ). The most significant results of one-way ANOVA are shown in Table 3 and results for all loci are shown in Additional file 3.

\section{Discussion}

Genes related to neurotransmission and neurotrophic function have been widely studied in various mood and behavior disorders. To confirm possible associations studied previously and find out new associations, we investigated SLC6A3 (40-45 bp. VNTR), DRD2 (rs1800497), DRD4 (In/Del 120 bp. and 48 bp. VNTR), COMT (rs4680), SLC6A4 (VNTR 44 bp. and rs25531), HTR1A (rs6295), HTR2A (rs6311), $H T R 1 B$ (rs6296) and BDNF (rs6264) polymorphic loci in patients with suicidal behavior. The study was carried out with a sample of patients who had attempted suicide at least two times. We have supposed that the repeated suicidal attempts are not the result of impulsivity or mood disorders only but show the genetic predisposition to suicidal behavior. We have found statistically significant associations between suicidal behavior and SLC6A3 (40 bp. VNTR), COMT (rs4680), SLC6A4 (rs25531), BDNF (rs6264) loci.

Although the association between SLC6A3 $40 \mathrm{bp}$. VNTR-polymorphism and mood disorders, as well as personality traits, was confirmed [27, 28], we do not know about research that studied an effect of this locus on suicidal tendencies. We discovered a strong association between short ( $\leq 9$ repeats) allele and suicidal behavior $(p=0.009)$. Carriers of at least one S-allele (SS and LS genotypes) have a significantly higher risk of suicide $(p=0.019)$. Given the data of low expression activity of the 9 R-allele [26], we can suppose that suicidal behavior may be associated with dopamine transporter deficiency and consequently with increased dopamine signalling.

Our research may complement the results of a meta-analysis that demonstrated that the COMT rs4680 polymorphism is associated with suicidal behavior [22]. The meta-analysis was performed on six studies and showed that Met (A) allele with low activity is associated with suicidal attempts. However, the authors draw attention to the dependence of the results on the inclusion of all six studies. When five of 
the six studies were individually excluded from the analysis, the relationship between COMT Met-allele and suicide was no longer significant. According to our results, suicidal behavior is associated with the COMT G-allele (Val) $(56,5 \%$ in cases vs. $46,6 \%$ in controls, $p=0,028)$. Taking these data into account, we can conclude that the COMT rs4680 polymorphism possibly does not affect suicidal behavior.

We also confirmed the results of a meta-analysis that showed the risk of suicide in carriers of the Metallele of $B D N F$ rs6264 [39]. The Met-allele was more common in the cases than in the control group (23\% vs. $16 \%, p=0,029)$.

We did not confirm the results of the meta-analysis that showed that the S-allele of the $44 \mathrm{bp}$. SLC6A4 VNTR-polymorphism is a risk factor for suicide [15]. As far as we know, the relationship between SLC6A4 rs25531 and suicidal attempts was not verified before. We have found that the rare G-allele was even rarer in cases ( $5 \%$ vs. $9.9 \%, p=0.047)$. We suppose this locus may contribute to predisposition to suicidal behavior together with other loci, but its contribution is small. A bigger sample is required to verify this association. We also tried to establish whether the effects of $44 \mathrm{bp}$ VNTR and rs25531 polymorphisms on SLC6A4 expression are associated with suicide. We classified alleles and genotypes according to their functional activity and did not find statistically significant associations (Table 2).

The effect of dopamine receptor genes polymorphism on suicidal behavior is not well understood. Although some studies have shown an association between DRD2 rs1800497 or haplotypes with this SNP and suicidal behavior [33,34] no differences between allelic and genotype frequencies of this locus in our samples of patients and controls were found. Just like our research, previous studies failed to find an association between DRD4 48 bp VNTR-polymorphism and suicidal attempts [29, 46]. We also did not find DRD4 In/Del $120 \mathrm{bp}$. to be associated with suicide. In our knowledge, this is the first study aimed to establish if the DRD4 in/del $120 \mathrm{bp}$. polymorphism related to suicidal behavior.

Our data on the lack of association between HTR1A (rs6295) and HTR1B (rs6296) polymorphisms and suicide are consistent with previous meta-analyses [21,22]. Contrary to the results of a meta-analysis showing a link between HTR2A (rs6311) and suicidal behavior [20], we did not find statistically significant differences.

It was previously shown that all of these genes are associated with major depression. We tried to verify if these loci affect severity of depressive symptoms. ANOVA showed the lack of association between these loci and depression symptoms, as well as with anxiety symptoms, but revealed an effect of SLC6A4 40 bp VNTR and HTR1B loci on situational and personal anxiety, respectively.

\section{Conclusions}

In this study, we show that polymorphism of the SLC6A4, SLC6A3, COMT and BDNF genes might be associated with the risk of suicidal behavior. For the first time, the effect of the dopamine transporter gene (SLC6A3) 40-45 bp VNTR-polymorphism on suicidal behavior was examined and we have found that a short allele may increase the risk of suicidal attempts. We also confirmed the results of previous 
studies of the $B D N F$ rs6264 locus, the T-allele of which is associated with suicide. In contrast to the metaanalysis of studies of the rs 4680 COMT gene polymorphism, which shows that the G-allele (Val) is associated with suicide, we obtained data on the possible association of suicidal behavior with the Metallele. The association of SLC6A4 rs25531 polymorphism with suicide was first studied, but because the $\mathrm{G}$-allele is rare in the population, this result requires verification on a large sample.

We showed that SLC6A4 40 bp VNTR and HTR1B loci might be related to severity of anxiety symptoms.

Further studies are required to verify if these polymorphic loci are associated with suicidal behavior only or if they might increase the risk of severe mental illness leading to suicide attempts.

\section{Abbreviations}

$\mathrm{OR}$ - odds ratio

$\mathrm{Cl}-$ confidence interval

VNTR - variable number tandem repeat

SNP - single nucleotide polymorphism

HAMD - Hamilton's Depression Rating Scale

BDI - Beck's Depression Inventory

\section{Declarations}

\section{Ethics approval and consent to participate}

All blood samples were collected with the informed consent of the investigated persons after participant's personal statement signature. The Ethics Committee of the Institute of Molecular Genetics (Institute of Molecular Genetics, Russian Academy of Sciences, Kurchatov sq. 2, Moscow, Russia) approved the study (protocol 03\19, 19 February 2019).

\section{Availability of data and materials}

All data generated or analysed during this study are included in this published article and its supplementary information files.

\section{Competing interests}

The authors declare that they have no conflict of interest. 


\section{Funding}

The present study was supported by the Russian Foundation for Basic Research (projects no. 19-0400383, no. 17-29-02203-ofi-m, no. 19-015-00380). The funding body played no role in the study design, the collection, analysis and interpretation of the data or the preparation and approval of the manuscript.

\section{Authors' contributions}

ER performed genotyping, statistical analysis, data interpretation, and wrote the original draft. MS performed DNA isolation and genotyping. PS contributed to conceptualization and edited the article. AG collected blood samples and patients data. AR contributed to conceptualization and edited the article. DS made contributions to the methodology and genotyping. VV led the investigation and made contributions to the funding acquisition, methodology, and design of the study. All authors have read and approved the manuscript.

\section{Acknowledgements}

The work was conducted on the base of the Center for Collective Use, Institute of Gene Biology, Russian Academy of Sciences (GK02.451.11.7060).

\section{References}

1. Fitzgerald P, Kulkarni J: Suicide rates and mental health disorder prevention. Aust $N Z J$ Psychiatry 2015, 49(1):91-92.

2. Baldessarini RJ, Hennen J: Genetics of suicide: an overview. Harv Rev Psychiatry 2004, 12(1):1-13.

3. Fu Q, Heath AC, Bucholz KK, Nelson EC, Glowinski AL, Goldberg J, Lyons MJ, Tsuang MT, Jacob T, True MR et al: A twin study of genetic and environmental influences on suicidality in men. Psychol Med 2002, 32(1):11-24.

4. Glowinski AL, Bucholz KK, Nelson EC, Fu Q, Madden PA, Reich W, Heath AC: Suicide attempts in an adolescent female twin sample. J Am Acad Child Adolesc Psychiatry 2001, 40(11):1300-1307.

5. Roy A, Segal NL: Suicidal behavior in twins: a replication. J Affect Disord 2001, 66(1):71-74.

6. von Borczyskowski A, Lindblad F, Vinnerljung B, Reintjes R, Hjern A: Familial factors and suicide: an adoption study in a Swedish National Cohort. Psychol Med 2011, 41(4):749-758.

7. Brent DA, Mann JJ: Family genetic studies, suicide, and suicidal behavior. Am J Med Genet C Semin Med Genet 2005, 133C(1):13-24.

8. Tidemalm D, Runeson B, Waern M, Frisell T, Carlstrom E, Lichtenstein P, Langstrom N: Familial clustering of suicide risk: a total population study of 11.4 million individuals. Psychol Med 2011, 41(12):2527-2534. 
9. Mann JJ, Henteleff RA, Lagattuta TF, Perper JA, Li S, Arango V: Lower 3H-paroxetine binding in cerebral cortex of suicide victims is partly due to fewer high affinity, non-transporter sites. $J$ Neural Transm (Vienna) 1996, 103(11):1337-1350.

10. Mann JJ, Malone KM: Cerebrospinal fluid amines and higher-lethality suicide attempts in depressed inpatients. Biol Psychiatry 1997, 41(2):162-171.

11. Sher L, Mann JJ, Traskman-Bendz L, Winchel R, Huang YY, Fertuck E, Stanley BH: Lower cerebrospinal fluid homovanillic acid levels in depressed suicide attempters. J Affect Disord 2006, 90(1):83-89.

12. Samuelsson M, Jokinen J, Nordstrom AL, Nordstrom P: CSF 5-HIAA, suicide intent and hopelessness in the prediction of early suicide in male high-risk suicide attempters. Acta Psychiatr Scand 2006, 113(1):44-47.

13. Lesch KP, Bengel D, Heils A, Sabol SZ, Greenberg BD, Petri S, Benjamin J, Muller CR, Hamer DH, Murphy DL: Association of anxiety-related traits with a polymorphism in the serotonin transporter gene regulatory region. Science 1996, 274(5292):1527-1531.

14. Heils A, Teufel A, Petri S, Stober G, Riederer P, Bengel D, Lesch KP: Allelic variation of human serotonin transporter gene expression. J Neurochem 1996, 66(6):2621-2624.

15. Li D, He L: Meta-analysis supports association between serotonin transporter (5-HTT) and suicidal behavior. Mol Psychiatry 2007, 12(1):47-54.

16. Czesak M, Lemonde S, Peterson EA, Rogaeva A, Albert PR: Cell-specific repressor or enhancer activities of Deaf-1 at a serotonin 1A receptor gene polymorphism. J Neurosci 2006, 26(6):18641871.

17. Lemonde S, Turecki G, Bakish D, Du L, Hrdina PD, Bown CD, Sequeira A, Kushwaha N, Morris SJ, Basak A et al: Impaired repression at a 5-hydroxytryptamine 1A receptor gene polymorphism associated with major depression and suicide. J Neurosci 2003, 23(25):8788-8799.

18. Duan J, Sanders AR, Molen JE, Martinolich L, Mowry BJ, Levinson DF, Crowe RR, Silverman JM, Gejman PV: Polymorphisms in the $5^{1}$-untranslated region of the human serotonin receptor 1B (HTR1B) gene affect gene expression. Mol Psychiatry 2003, 8(11):901-910.

19. Parsons MJ, D'Souza UM, Arranz MJ, Kerwin RW, Makoff AJ: The -1438A/G polymorphism in the 5hydroxytryptamine type 2A receptor gene affects promoter activity. Biol Psychiatry 2004, 56(6):406410.

20. Li D, Duan Y, He L: Association study of serotonin 2A receptor (5-HT2A) gene with schizophrenia and suicidal behavior using systematic meta-analysis. Biochem Biophys Res Commun 2006, 340(3):1006-1015.

21. Gonzalez-Castro TB, Tovilla-Zarate CA, Juarez-Rojop I, Pool Garcia S, Genis A, Nicolini H, Lopez Narvaez L: Association of 5HTR1A gene variants with suicidal behavior: case-control study and updated meta-analysis. J Psychiatr Res 2013, 47(11):1665-1672.

22. Kia-Keating BM, Glatt SJ, Tsuang MT: Meta-analyses suggest association between COMT, but not HTR1B, alleles, and suicidal behavior. Am J Med Genet B Neuropsychiatr Genet 2007, 144B(8):1048- 
1053.

23. Fuke S, Suo S, Takahashi N, Koike H, Sasagawa N, Ishiura S: The VNTR polymorphism of the human dopamine transporter (DAT1) gene affects gene expression. Pharmacogenomics J 2001, 1(2):152156.

24. Inoue-Murayama M, Adachi S, Mishima N, Mitani H, Takenaka O, Terao K, Hayasaka I, Ito S, Murayama Y: Variation of variable number of tandem repeat sequences in the 3'-untranslated region of primate dopamine transporter genes that affects reporter gene expression. Neurosci Lett 2002, 334(3):206-210.

25. Miller GM, Madras BK: Polymorphisms in the 3'-untranslated region of human and monkey dopamine transporter genes affect reporter gene expression. Mol Psychiatry 2002, 7(1):44-55.

26. VanNess SH, Owens MJ, Kilts CD: The variable number of tandem repeats element in DAT1 regulates in vitro dopamine transporter density. BMC Genet 2005, 6:55.

27. Bielinski M, Jaracz M, Lesiewska N, Tomaszewska M, Sikora M, Junik R, Kaminska A, Tretyn A, Borkowska A: Association between COMT Val158Met and DAT1 polymorphisms and depressive symptoms in the obese population. Neuropsychiatr Dis Treat 2017, 13:2221-2229.

28. Joyce PR, McHugh PC, Light KJ, Rowe S, Miller AL, Kennedy MA: Relationships between angryimpulsive personality traits and genetic polymorphisms of the dopamine transporter. Biol Psychiatry 2009, 66(8):717-721.

29. Zalsman G, Frisch A, Lewis R, Michaelovsky E, Hermesh H, Sher L, Nahshoni E, Wolovik L, Tyano S, Apter A et al: DRD4 receptor gene exon III polymorphism in inpatient suicidal adolescents. J Neural Transm (Vienna) 2004, 111(12):1593-1603.

30. Munafo MR, Yalcin B, Willis-Owen SA, Flint J: Association of the dopamine D4 receptor (DRD4) gene and approach-related personality traits: meta-analysis and new data. Biol Psychiatry 2008, 63(2):197-206.

31. D'Souza UM, Russ C, Tahir E, Mill J, McGuffin P, Asherson PJ, Craig IW: Functional effects of a tandem duplication polymorphism in the 5'flanking region of the DRD4 gene. Biol Psychiatry 2004, 56(9):691-697.

32. Thompson J, Thomas N, Singleton A, Piggott M, Lloyd S, Perry EK, Morris CM, Perry RH, Ferrier IN, Court JA: D2 dopamine receptor gene (DRD2) Taq1 A polymorphism: reduced dopamine D2 receptor binding in the human striatum associated with the A1 allele. Pharmacogenetics 1997, 7(6):479-484.

33. Suda A, Kawanishi C, Kishida I, Sato R, Yamada T, Nakagawa M, Hasegawa H, Kato D, Furuno T, Hirayasu Y: Dopamine D2 receptor gene polymorphisms are associated with suicide attempt in the Japanese population. Neuropsychobiology 2009, 59(2):130-134.

34. Jasiewicz A, Samochowiec A, Samochowiec J, Malecka I, Suchanecka A, Grzywacz A: Suicidal behavior and haplotypes of the dopamine receptor gene (DRD2) and ANKK1 gene polymorphisms in patients with alcohol dependence-preliminary report. PLoS One 2014, 9(11):e111798.

35. Lachman HM, Papolos DF, Saito T, Yu YM, Szumlanski CL, Weinshilboum RM: Human catechol-0methyltransferase pharmacogenetics: description of a functional polymorphism and its potential 
application to neuropsychiatric disorders. Pharmacogenetics 1996, 6(3):243-250.

36. Duman RS: Synaptic plasticity and mood disorders. Mol Psychiatry 2002, 7 Suppl 1:S29-34.

37. Mattson MP, Maudsley S, Martin B: BDNF and 5-HT: a dynamic duo in age-related neuronal plasticity and neurodegenerative disorders. Trends Neurosci 2004, 27(10):589-594.

38. Shadrina M, Bondarenko EA, Slominsky PA: Genetics Factors in Major Depression Disease. Front Psychiatry 2018, 9:334.

39. Zai CC, Manchia M, De Luca V, Tiwari AK, Chowdhury NI, Zai GC, Tong RP, Yilmaz Z, Shaikh SA, Strauss $\mathrm{J}$ et al: The brain-derived neurotrophic factor gene in suicidal behaviour: a meta-analysis. Int J Neuropsychopharmacol 2012, 15(8):1037-1042.

40. Butovskaya ML, Butovskaya PR, Vasilyev VA, Sukhodolskaya JM, Fekhredtinova DI, Karelin DV, Fedenok JN, Mabulla AZP, Ryskov AP, Lazebny OE: Serotonergic gene polymorphisms (5-HTTLPR, 5HTR1A, 5HTR2A), and population differences in aggression: traditional (Hadza and Datoga) and industrial (Russians) populations compared. J Physiol Anthropol 2018, 37(1):10.

41. Fekhretdinova DI, Sukhodolskaya EM, Shibalev DV, Lazebnyy OE, Butovskaya ML, Ryskov AP, Vasil'yev VA: Polymorphism of the Two Genes Encoding Catecholamine Degradation Enzymes (COMT and MAOA) in the Hadza and Datoga African Ethnic Populations. Mol Genet Microbiol+ 2018, 33(3):195-200.

42. Sukhodolskaya EM, Fehretdinova DI, Shibalev DV, Lazebny OE, Mabulla AZP, Butovskaya ML, Ryskov AP, Vasilyev VV: Polymorphisms of dopamine receptor genes DRD2 and DRD4 in African populations of Hadza and Datoga differing in the level of culturally permitted aggression. Ann Hum Genet 2018, 82(6):407-414.

43. Sukhodolskaya EM, Vasilyev VA, Shibalev DV, Shcherbakova OI, Kulikov AM, Lazebny OE, Karelin DV, Butovskaya ML, Ryskov AP: [Comparative Analysis of Polymorphisms of the Serotonin Receptor Genes HTR1A, HTR2A, and HTR1B in Hadza and Datoga Males]. Genetika 2015, 51(11):1308-1314.

44. Sukhodol'skaia EM, Vasil'ev VA, Shibalev DV, Shcherbakova OI, Kulikov AM, Lazebnyi OE, Dronova DA, Butovskaia ML, Ryskov AP: [The 3'-UTR polymorphism of dopamine transporter gene in hadza and datoga males]. Mol Biol (Mosk) 2014, 48(2):295-299.

45. Bondarenko EA, Shadrina MI, Grishkina MN, Druzhkova TA, Akzhigitov RG, Gulyaeva NV, Guekht AB, Slominsky PA: Genetic Analysis of BDNF, GNB3, MTHFR, ACE and APOE Variants in Major and Recurrent Depressive Disorders in Russia. Int J Med Sci 2016, 13(12):977-983.

46. Doorley J, Williams C, Mallard T, Esposito-Smythers C, McGeary J: Sexual Trauma, the Dopamine D4 Receptor, and Suicidal Ideation Among Hospitalized Adolescents: A Preliminary Investigation. Arch Suicide Res 2017, 21(2):279-292.

\section{Tables}

Table 1. Demographic and psychiatric characteristics of patients 


\begin{tabular}{|c|c|c|}
\hline \multirow[t]{3}{*}{$n$} & total & 100 \\
\hline & female & 80 \\
\hline & male & 20 \\
\hline \multirow[t]{3}{*}{ Age, years } & $\min$ & 18 \\
\hline & $\max$ & 77 \\
\hline & mean & 31.54 \\
\hline \multirow[t]{3}{*}{ BDI } & $\min$ & 8 \\
\hline & $\max$ & 53 \\
\hline & mean & 28.85 \\
\hline \multirow[t]{3}{*}{ HAMD } & $\min$ & 7 \\
\hline & $\max$ & 35 \\
\hline & mean & 21.19 \\
\hline \multirow[t]{3}{*}{ Situational anxiety } & $\min$ & 25 \\
\hline & $\max$ & 80 \\
\hline & mean & 55.52 \\
\hline \multirow[t]{3}{*}{ Personal anxiety } & $\min$ & 25 \\
\hline & $\max$ & 80 \\
\hline & mean & 56.44 \\
\hline
\end{tabular}

Table 2. Genotype and allele frequency of SLC6A4, HTR1A, HTR2A, HTR1B, SLC6A3, DRD4, DRD2, COMT and $B D N F$ genes in patients with suicidal behavior 


\begin{tabular}{|c|c|c|c|c|}
\hline \multirow[t]{2}{*}{ Genotype/Allele } & \multicolumn{2}{|l|}{ Total. $\mathbf{n}(\%)$} & \multirow[t]{2}{*}{$\chi 2$ (p-value) } & \multirow[t]{2}{*}{ ORs } \\
\hline & Control & Suicide & & \\
\hline \multicolumn{5}{|c|}{ SLC6A3 40 bp VNTR* } \\
\hline$L L$ & $113(69.3)$ & $52(52)$ & \multirow[t]{3}{*}{$7.96(0.019)++$} & 0.48 \\
\hline$\angle S$ & $46(28.2)$ & $44(44)$ & & 1.998 \\
\hline$S S$ & $4(2.5)$ & $4(4)$ & & 0.6 \\
\hline$L$ & $272(83.4)$ & $148(74)$ & \multirow[t]{2}{*}{$6.86(0.009)++$} & 0.565 \\
\hline$s$ & $54(16.6)$ & $52(26)$ & & 1.77 \\
\hline \multicolumn{5}{|l|}{ COMT rs4680 } \\
\hline$A A(M e t / M e t)$ & $48(29.4)$ & $17(17)$ & \multirow[t]{3}{*}{$5.51(0.064)+$} & 0.49 \\
\hline GA (Val/Met) & $78(47.9)$ & $53(53)$ & & 1.23 \\
\hline GG (Val/Val) & $37(22.7)$ & $30(30)$ & & 1.46 \\
\hline$A($ Met $)$ & $174(53.4)$ & $87(43.5)$ & \multirow[t]{2}{*}{$4.83(0.028)++$} & 0.67 \\
\hline$G(\mathrm{Val})$ & $152(46.6)$ & $113(56.5)$ & & 1.49 \\
\hline \multicolumn{5}{|l|}{ BDNF rs6264 } \\
\hline CC (Val/Val) & $183(70.7)$ & $61(61)$ & \multirow[t]{3}{*}{$5.14(0.076)+$} & 0.65 \\
\hline CT ( Val/Met) & $69(26.6)$ & $32(32)$ & & 1.3 \\
\hline$T T$ (Met/Met) & $7(2.7)$ & $7(7)$ & & 2.71 \\
\hline$C(\mathrm{Val})$ & $435(84)$ & $154(77)$ & \multirow[t]{2}{*}{$4.77(0.029)++$} & 0.64 \\
\hline$T($ Met $)$ & $83(16)$ & $46(23)$ & & 1.56 \\
\hline \multicolumn{5}{|l|}{ SLC6A4 rs25531 } \\
\hline$A A$ & $129(82.2)$ & $90(90)$ & \multirow[t]{3}{*}{$3.92(0.141)$} & 1.95 \\
\hline$A G$ & $25(15.9)$ & $10(10)$ & & 0.59 \\
\hline$G G$ & $3(1.9)$ & 0 & & 0.22 \\
\hline$A$ & $283(90.1)$ & $190(95)$ & \multirow[t]{2}{*}{$3.95(0.047)++$} & 2.08 \\
\hline$G$ & $31(9.9)$ & $10(5)$ & & 0.48 \\
\hline \multicolumn{5}{|c|}{ SLC6A4 VNTR 44 bp } \\
\hline$L L$ & $68(43.3)$ & $41(41)$ & \multirow[t]{2}{*}{$4.18(0.12)$} & 0.91 \\
\hline$L S$ & $59(37.6)$ & $48(48)$ & & 1.53 \\
\hline
\end{tabular}




\begin{tabular}{|c|c|c|c|c|}
\hline SS & $30(19.1)$ & $11(11)$ & & 0.52 \\
\hline$L$ & $195(62.1)$ & $130(65)$ & \multirow[t]{2}{*}{$0.44(0.507)$} & 1.13 \\
\hline$s$ & $119(37.9)$ & $70(35)$ & & 0.88 \\
\hline \multicolumn{5}{|c|}{ SLC6A4 VNTR 44 bp + rs25531 ** } \\
\hline high/high & $49(31.2)$ & $35(35)$ & \multirow[t]{3}{*}{$4.45(0.108)$} & 1.19 \\
\hline high/low & $67(42.7)$ & $50(50)$ & & 1.34 \\
\hline low/low & $41(26.1)$ & $15(15)$ & & 0.5 \\
\hline high & $165(52.5)$ & $120(60)$ & \multirow[t]{2}{*}{$2.75(0.098)+$} & 1.35 \\
\hline low & $149(47.5)$ & $80(40)$ & & 0.74 \\
\hline \multicolumn{5}{|c|}{ DRD2 rs1800497 } \\
\hline$C C$ & $95(58.3)$ & $48(48)$ & \multirow[t]{3}{*}{$2.85(0.241)$} & 0.66 \\
\hline$C T$ & $63(38.6)$ & $47(47)$ & & 1.41 \\
\hline$T T$ & $5(3.1)$ & $5(5)$ & & 1.66 \\
\hline$C$ & $253(77.6)$ & $143(71.5)$ & \multirow[t]{2}{*}{$2.48(0.115)$} & 0.72 \\
\hline$T$ & $73(22.4)$ & $57(28.5)$ & & 1.38 \\
\hline \multicolumn{5}{|c|}{ DRD4 $120 \mathrm{bp}$ In/Del } \\
\hline$L L$ & $116(71.2)$ & $75(75)$ & \multirow[t]{3}{*}{$0.82(0.664)$} & 1.22 \\
\hline$L S$ & $41(25.1)$ & $23(23)$ & & 0.89 \\
\hline$S S$ & $6(3.7)$ & $2(2)$ & & 0.53 \\
\hline$L$ & $273(83.7)$ & $173(86.5)$ & \multirow[t]{2}{*}{$0.73(0.393)$} & 1.24 \\
\hline$S$ & $53(16.3)$ & $27(13.5)$ & & 0.8 \\
\hline \multicolumn{5}{|c|}{ DRD4 48 bp VNTR *** } \\
\hline SS & $114(71.7)$ & $67(67)$ & \multirow[t]{3}{*}{$1.77(0.414)$} & 0.8 \\
\hline LS & $41(25.8)$ & $32(32)$ & & 1.35 \\
\hline LL & $4(2.5)$ & $1(1)$ & & 0.39 \\
\hline$S$ & $269(84.6)$ & $166(83)$ & \multirow[t]{2}{*}{$0.23(0.631)$} & 0.89 \\
\hline$L$ & $49(15.4)$ & $34(17)$ & & 1.12 \\
\hline \multicolumn{5}{|c|}{ HTR1A rs6295 } \\
\hline$C C$ & $42(25.8)$ & $23(23)$ & $2.14(0.343)$ & 0.86 \\
\hline
\end{tabular}




\begin{tabular}{|c|c|c|c|c|}
\hline$C G$ & $91(55.8)$ & $51(51)$ & & 0.82 \\
\hline$G G$ & 30 (18.4) & $26(26)$ & & 1.56 \\
\hline C & 175 (53.7) & 97 (48.5) & \multirow[t]{2}{*}{$1.33(0.248)$} & 0.81 \\
\hline G & $151(46.3)$ & $103(51.5)$ & & 1.23 \\
\hline \multicolumn{5}{|c|}{ HTR2A rs6311 } \\
\hline GG & $63(38.6)$ & $43(43)$ & \multirow[t]{3}{*}{$2.61(0.271)$} & 1.2 \\
\hline$A G$ & 72 (44.2) & $47(47)$ & & 1.12 \\
\hline$A A$ & $28(17.2)$ & $10(10)$ & & 0.54 \\
\hline G & $198(60.7)$ & $133(66.5)$ & \multirow[t]{2}{*}{$1.77(0.184)$} & 1.28 \\
\hline$A$ & 128 (39.3) & $67(33.5)$ & & 0.78 \\
\hline \multicolumn{5}{|c|}{ HTR1B rs6296 } \\
\hline GG & $81(49.7)$ & $57(57)$ & \multirow[t]{3}{*}{$2.31(0.315)$} & 1.34 \\
\hline$C G$ & 69 (42.3) & 39 (39) & & 0.87 \\
\hline$C C$ & $13(8)$ & $4(4)$ & & 0.48 \\
\hline G & 231 (70.9) & 153 (76.5) & \multirow[t]{2}{*}{$2(0.157)$} & 1.34 \\
\hline C & $95(29.1)$ & $47(23.5)$ & & 0.75 \\
\hline
\end{tabular}

The most significant results marked $+p<0.1,++p<0.05$

*-genotypes classified as LL, LS and $S S(L \geq 10,<10)$

**-genotypes classified as LL, LS and $S S(L \geq 7, S<7)$

$\star \star \star-$ genotypes classified according to their expressional activity

Table 3. One-way ANOVA. Effects of gene polymorphisms on the depression and anxiety symptoms 


\begin{tabular}{|c|c|c|c|c|}
\hline Source of variability & SS & DF & $\mathbf{F}$ & $\mathbf{P}$ \\
\hline \multicolumn{5}{|l|}{ Depression symptoms, Beck scale } \\
\hline SLC6A3 40 bp VNTR* & 455,9 & 2 & 2,0572 & 0,0824 \\
\hline Error & 7353,0 & 83 & & \\
\hline \multicolumn{5}{|c|}{ Depression symptoms, Hamilton scale } \\
\hline HTR1A & 108,1 & 2 & 2,0277 & 0,1381 \\
\hline Error & 2211,6 & 83 & & \\
\hline \multicolumn{5}{|l|}{ Situational anxiety } \\
\hline DRD4 48 bp VNTR** & 741,7 & 2 & 2,2842 & 0,1082 \\
\hline Error & 13475,7 & 83 & & \\
\hline SLC6A4 44 bp VNTR + rs25531*** & 757,3 & 2 & 2,3348 & 0,1032 \\
\hline Error & 13460,2 & 83 & & \\
\hline SLC6A4 44 bp VNTR & 1096,3 & 2 & 3,4675 & 0,0358 \\
\hline Error & 13121,1 & 83 & & \\
\hline \multicolumn{5}{|l|}{ Personal anxiety } \\
\hline COMT & 422,0 & 2 & 2,1451 & 0,1236 \\
\hline Error & 8064,9 & 82 & & \\
\hline SLC6A4 44 bp VNTR + rs25531*** & 454,7 & 2 & 2,3208 & 0,1046 \\
\hline Error & 8032,2 & 82 & & \\
\hline SLC6A4 44 bp VNTR & 441,7 & 2 & 2,2508 & 0,1118 \\
\hline HTR1B & 850,7 & 2 & 4,5678 & 0,0132 \\
\hline Error & 7636,2 & 82 & & \\
\hline
\end{tabular}

Statistically significant results are in bold

DF - degrees of freedom, SS - sum of squares, F - F-test, P - probability

*-genotypes classified as LL, LS and SS $(L \geq 10,<10)$

**-genotypes classified as LL, LS and $S S(L \geq 7, S<7)$

*** - genotypes classified as high/high, high/low and low/low according to expressional activity 


\section{Supplementary Files}

This is a list of supplementary files associated with this preprint. Click to download.

- Additionalfile3.xlsx

- Additionalfile2.xIsx

- Additionalfile1.xlsx 